\title{
Gender Differences in Students' Mathematics Game Playing
}

Tom Lowrie ${ }^{\mathrm{a}}$

Robyn Jorgensen ${ }^{\mathrm{b}}$

${ }^{a}$ Research Institute for Professional Practice, Learning and Education, Charles Sturt University, Wagga Wagga, Australia, tlowrie@csu.edu.au

${ }^{b}$ Griffith Institute for Educational Research, Griffith University, Brisbane, Australia, r.jorgensen@griffith.edu.au

Corresponding author:

Professor Tom Lowrie

Charles Sturt University,

Locked Bag 588,

Wagga Wagga, NSW 2678, AUSTRALIA

Electronic mail: tlowrie@csu.edu.au

Telephone: +61269334328

Facsimile: +61 269332962 


\begin{abstract}
The investigation monitored the digital game-playing behaviours of 428 primary-aged students (aged 10-12 years). Chi square analysis revealed that boys tend to spend more time playing digital games than girls while boys and girls play quite different game genres. Subsequent analysis revealed statistically significant gender differences in terms of the types of mathematics-rich games students prefer to play. Girls preferred to play games that required problem solving, quantitative computations and the interpretation of graphs. Boys preferred games that required the decoding and encoding of maps. Given the fact that boys outperform girls of spatial tasks and mathematics assessment items that contain graphics, this study has implications for the development of students mathematics sense making.
\end{abstract}

Key words:

Gender studies

Elementary education

Pedagogical issues

Numeracy practices 


\section{Gender Differences in Students Mathematics Game Playing}

\section{Introduction}

The connection between children's play and the development of mathematical thinking and understanding is not a new phenomenon. Childhood activities including play with water, blocks (Jarrell, 1998), and construction toys such as Lego (Lowrie, 2002), provide opportunities for game-play contexts which stimulate mathematical thinking. Provided these game-play opportunities are "embedded in cultural practices that make sense to the participants" meaningful learning can take place-even if the practices are in simulated forms” (van Oers, 2010). Recent technological advances, particularly in relation to visual and spatial stimuli, have extended the opportunities and possibilities of game playing. Indeed, a range of children's games that were previously only in a concrete (threedimensional) form, are now reproduced in digital forms (e.g., puzzles, board games, and sporting activities). To some extent, these activities require different forms of processing and thinking (Gee, 2007). In addition, some digital games go beyond the representational scope of more traditional games, with opportunities for dynamic representations of information increasingly available. These digital-rich contexts present the opportunity for meaningful mathematics engagement both within the confines of the game and beyondand consequently become a catalyst for meaning making (Lowrie, 2003). As such, 'new' technologies, and the patterns of individuals' social behaviour(s) have an influence on children's mathematics engagement. This investigation describes primary-aged students engagement in games-based technologies and considers the impact such technologies have on mathematics engagement.

\section{Background of the study}

To date, digital games tend to attract a predominately male audience, which not only has an impact on a potentially untapped market (Ziemek, 2006), but also affects girls' technology attitudes and experiences. At a stage when girls are disengaging with mathematics (Fennema, 1996), they are also electing not to spend as much time on twodimensional and three-dimensional game environments (Ziemek, 2006). Since digital games have the potential to improve some kinds of visuospatial reasoning (Guven \& Kosa, 2008), further research on the types of games students play is necessary. 
An extensive body of literature has examined the performance differences between males and females on non-verbal or spatial tasks. Although performance differences are widely acknowledged (Linn \& Petersen, 1985), the ongoing prevalence of such differences is far from stable. Spelke (2005), for example, indicated that the gap between the performance of boys and girls on visuospatial reasoning tasks had diminished in the past ten years. Nevertheless, boys tend to perform better on tasks that require mental rotations or when tasks encourage the manipulation of objects in the mind (Spelke, 2005). Such tasks are often required in digital game environments and are increasingly necessary in the interpretation of mathematics tasks (Lowrie \& Logan, 2007). With respect to primary-aged students (aged 9-12 years) there are significant gender differences in favour of boys on mathematics tasks that contain number lines and maps (Lowrie \& Diezmann, 2011; Lowrie \& Diezmann, 2007).

There are a number of plausible reasons for performance differences of males and females on these mathematics tasks. Explanations include the confidence levels of girls (Forgasz, Leder, \& Kaur, 2001); their attitudes toward mathematics (Forgasz, Leder, \& Kloosterman, 2004); and the fact that boys tend to process rotation tasks more quickly than girls (Wiedenbauer \& Jansen-Osmann, 2008). Other accounts include the view that boys' and girls' everyday experiences are different (Tracey, 1990); the age of students (Levine, Huttenlocher, Taylor, \& Langrock, 1999); or a combination of life experiences and inferentially biological propensities (Halpern \& Tan, 2001). In the pre-school years, it was found that very young children engage with digital environments in clearly gendered ways (Zevenbergen \& Logan, 2008).

Primary-aged students, in particular, are exposed to much more graphically- and visually-rich mathematics tasks than ever before. The ability to decode representations such as graphs, diagrams, and maps are essential to mathematics sense making (National Council of Teachers of Mathematics, 2000). At the same time, digital games are becoming much more graphically rich, with multiple forms of visual displays representing information on any given screen. The nexus between representation trends in mathematics and game playing is noteworthy since "computer-games experience and preference seems to serve as a mediator between gender and mental-rotation performance” (Quaiser-Pohl et al, 2006, p. 617). As Bananno \& Kommers (2005) argued: 
while males excel on tasks that benefit from requiring new strategies, such as mental rotation ability, females tend to draw on memory of past algorithms or knowledge such as verbal fluency, rather than inventing new approaches. (p. 36)

In studies with older students, it seems that females prefer playing games that involve logic (Quaiser-Pohl et al, 2006) and games which promote skills such as perceptual speed and time skills (Ziemele, 2006). By contrast, males prefer games which are graphically sophisticated and often involve competitive traits (Hartmann, 2003). Similar trends were observed with children under five as they engaged in digital environments (Zevenbergen, 2007). This investigation goes beyond studies which describe game-playing preference by not only considering the specific features of games students play but also determining the types of mathematics sense making accessed and promoted in the digital games students play.

The study, therefore, investigates primary-aged students' preference for playing specific types of digital games, with a focus on the mathematics sense making required to engage with some of the games. Specifically the study considers:

1. Whether there are gender differences in the amount of time primary-aged students spend playing digital games?

2. Whether there are differences in the type of game genre boys and girls elect to play at this age?

3. To what extent gender differences exist in relation to the type of mathematics sense making promoted in the games primary-aged students play?

\section{Method}

The project focused on the development and subsequent implementation of a Digital Landscape survey with primary school students. Data from the survey were analysed to address the three research questions of the study.

\subsection{Participants}

The participants who took part in the survey were 428 primary-aged students from two states in Australia. One cohort were from a rural inland city in New South Wales $(\mathrm{n}=241)$ and the other an urban coastal city in Queensland $(\mathrm{n}=187)$. The sample was purposively selected from a general expression of "participation interest" from schools in both catholic education and state systems. The participants were aged 10 to 12 years from Grades 5 and 
6. The questionnaire was administered to all Grade 5 and 6 students at the respective schools $(n=428)$, with students completing the questionnaire at home once parental consent had been received.

\subsection{Survey development}

The survey was designed to describe the nature of student engagement with a range of entertainment-based digital games with specific reference to mathematics content. The survey sought information that would provide patterns of student behaviour in relation to preference for types of games consoles and software, duration and sequencing of game playing, and the content and processes involved in playing the games. The survey used in this study was based on the British Educational Technologies and Communications Agency (BECTA) (2002) questionnaire on Young People’s Use of ICT and adapted specifically for this study. The instrument contained 3 sections associated with digital hardware and software, game-playing habits and the learning principles of the games. The survey included 24 items in three forms: (1) a 3-point categorical format which sought to identify duration and sequencing of game play; (2) a 5-point Likert scale (in the form frequently through to never); and (3) short answer responses. Descriptive data were also collated and included students' grade level and gender.

Before the survey was administered to students, the items were reviewed by two content experts outside of the research team. In addition, an earlier version of the instrument was trialled with a small cohort of students $(n=23)$. The central aim of the piloting process was to ensure readability and appropriateness, with this cohort also interviewed about the content and nature of the survey to ensure questions were valid. Based upon the feedback provided by the students and content experts, some of the items were removed or rephrased.

\section{Results and Discussion}

\section{1. $\quad$ Time spent playing digital games}

Three $2 \times 3$ contingency table analyses were conducted to determine the relationship between gender and time spent playing digital games. In terms of time spent playing games

per week, the Fisher's Chi-square value $\chi^{2}(2,425)=13.89, \mathrm{p}<.01$ revealed a statistically significant relationship between gender and time spent playing games. $49 \%$ of boys played 
digital games for more than 3 days per week (as opposed to $32 \%$ of girls) while only $22 \%$ of boys played games for less than 1 day per week. In relation the days in which these games were played, there was no relationship between gender and game play on school days $\chi^{2}(2,425)=5.01, \mathrm{p}>.05$; however there was a statistically significant relationship between gender and game play on non-school days $\chi^{2}(2,425)=22.20, p<.01$. Within the non-school day category, 34\% of boys spent more than three hours playing games per day (girls $16 \%$ ) while $44 \%$ of girls spent less than one hour playing games per non-school day (29\% of boys).

Table 1

Contingency Table and Chi Square Analysis for Time Spent Playing Games by Gender

\begin{tabular}{|c|c|c|c|c|}
\hline & & $\begin{array}{c}\text { Boys } \\
\text { Frequency } \\
(\%)\end{array}$ & $\begin{array}{c}\text { Girls } \\
\text { Frequency } \\
(\%)\end{array}$ & $\begin{array}{l}\text { Chi Square } \\
D f(2,425)\end{array}$ \\
\hline \multirow[t]{4}{*}{$\begin{array}{l}\text { No. days per } \\
\text { week }\end{array}$} & & & & $\begin{array}{c}\chi^{2}=13.89, \mathrm{p}<.01 \\
\text { E.S }=.18\end{array}$ \\
\hline & $<1$ day & $\begin{array}{c}44 \\
(22)\end{array}$ & $\begin{array}{c}73 \\
(32)\end{array}$ & \\
\hline & 1-3 days & $\begin{array}{c}57 \\
(29)\end{array}$ & $\begin{array}{c}80 \\
(36)\end{array}$ & \\
\hline & $>3$ days & $\begin{array}{c}99 \\
(49)\end{array}$ & $\begin{array}{c}72 \\
(32)\end{array}$ & \\
\hline \multirow[t]{3}{*}{$\begin{array}{l}\text { No. hours on a } \\
\text { school days }\end{array}$} & & & & $\begin{array}{c}\chi^{2}=5.01, p>.05 \\
\text { E.S }=.11\end{array}$ \\
\hline & $<1$ hour & $\begin{array}{l}119 \\
(60)\end{array}$ & $\begin{array}{l}155 \\
(70)\end{array}$ & \\
\hline & $\begin{array}{l}\text { Between 1-3 } \\
\text { hours } \\
\text { >3 days }\end{array}$ & $\begin{array}{c}66 \\
(33) \\
14 \\
(7)\end{array}$ & $\begin{array}{c}58 \\
(26) \\
9 \\
(4)\end{array}$ & \\
\hline \multirow[t]{5}{*}{$\begin{array}{l}\text { No. hours on } \\
\text { non-school days }\end{array}$} & & & & $\begin{array}{c}\chi^{2}=22.20, p<.01 \\
\text { E.S }=.22\end{array}$ \\
\hline & $<1$ hour & $\begin{array}{c}58 \\
(29)\end{array}$ & $\begin{array}{c}99 \\
(44)\end{array}$ & \\
\hline & Between 1-3 & 74 & 90 & \\
\hline & hours & (37) & (40) & \\
\hline & $>3$ hours & $\begin{array}{c}69 \\
(34)\end{array}$ & $\begin{array}{c}35 \\
(16)\end{array}$ & \\
\hline
\end{tabular}

Of particular note in these analyses is the fact that there is no relationship between gender and hours of digital game play on schools days. Although boys tended to spend more time 
of game play on school days, it was on non-school days where the significant gender differences occurred.

\subsection{Game type preference}

A 2 x 6 contingency table analysis was conducted to determine the extent to which there was an association between gender and preference among six type of game genre. The Fisher's Chi-square value $\chi^{2}(5,367)=61.6, \mathrm{p}<.001$ was statistically significant at a $\mathrm{p}=.05$ level and therefore there was relationship between gender and game genre. The effect size of .41 indicated a medium effect size. Boys were much more inclined to play games within the action category (25\% for boys as opposed to $4 \%$ for girls) while girls preferred games classified as other (29\% for girls and $7 \%$ for boys). Games within the 'Action’ category included Spyro (Activision, 2008) and Medal of Honour (Electronic Arts, 1999), whilst games within the 'Other' category included Brain Training (Nintendo, 2006) and Buzz! (Sony Computer Entertainment Europe, 2005).

Table 2

Contingency Table and Chi Square Analysis for Favourite Computer Game by Gender

What is your favourite computer game? Frequency (\%)

\begin{tabular}{lccccccc} 
Gender & Action & Adventure & Simulation & Strategy & Role playing & Other & Total \\
\hline Boys & 46 & 38 & 77 & 0 & 10 & 13 & 184 \\
& $(25)$ & $(21)$ & $(42)$ & $(0)$ & $(5)$ & $(7)$ & $(100)$ \\
Girls & 7 & 35 & 83 & 3 & 2 & 53 & 183 \\
& $(4)$ & $(19)$ & $(45)$ & $(2)$ & $(1)$ & $(29)$ & $(100)$ \\
Total & 53 & 73 & 160 & 3 & 12 & 66 & \\
& $(100)$ & $(100)$ & $(100)$ & $(100)$ & $(100)$ & $(100)$ & \\
\hline
\end{tabular}

Chi Square $=61.6, \mathrm{p}<.001$

\subsubsection{Mathematics ideas within digital games}

An Exploratory Factor Analysis was conducted on the four survey questions constructed to determine preference for playing digital games which involved mathematics ideas and concepts. This data reduction analysis was conducted before analysing the survey data to ensure the reliability of the subsequent univariate analysis (Hair et al, 1998). Principal-component factor analysis with varimax rotation revealed two factors with eigenvalues greater than 1.00 . The factor structure accounted for $76 \%$ of the variance and 
included attitude factors associated with the mathematics processes $47 \%$ and map representations $30 \%$. The items and factor loadings for the four questions can be seen in Table 3.

Table 3

Rotated Component Matrix

\begin{tabular}{|c|c|c|c|}
\hline Item & 1 & 2 & Component \\
\hline $\begin{array}{l}\text { How often do the games you play require you to } \\
\text { do maths problems? }\end{array}$ & .89 & & Maths Curriculum \\
\hline $\begin{array}{l}\text { How often do the games you play require you to } \\
\text { do maths algorithms or calculations? }\end{array}$ & .82 & & Maths Curriculum \\
\hline How often do they require you to read graphs? & .62 & .44 & Maths Curriculum \\
\hline How often do they require you to read maps? & & .96 & General Maps Skills \\
\hline
\end{tabular}

The questionnaire items have high loadings with factors that make conceptual sense with all loadings $>.6$ on a respective factor. The first factor consisted of items typically associated with strands in the mathematics curriculum (i.e., problem solving, number and measurement) while the second factor was restricted to the questions concerning maps. Although map items require high levels of spatial reasoning, they are seldom used by teachers to promote mathematics concepts (Lowrie \& Logan, 2007). Consequently, the two factors could be regarded as curriculum-based mathematics and general mapping skills.

An Analysis of Variance (ANOVA) was then used to determine whether student attitudes by gender differed across the two factors generated from the data reduction technique. Thus, game playing preference of boys and girls were compared across the preference dimensions associated with 1) mathematics curriculum content; and 2) general map skills. Table 4 shows the means and standard deviations by gender across the two preference dimensions. The scores were calculated by generating a mean score for the high-loading items for each of the two variables. Since the sub-scales did not contain the same items mean scores were used to facilitate comparisons. Items were scored in the same direction such that a 5 represented frequently requiring the use of the mathematics “process” whereas a 1 indicated rarely requiring such activity. 
Table 4

Means and Standard Deviations for the Mathematics and Map Variables by Gender

\begin{tabular}{lccc}
\hline & $\mathrm{N}$ & $\begin{array}{c}\text { Mathematics } \\
\text { Curriculum }\end{array}$ & Mapping Skills \\
\hline \multirow{2}{*}{ Boys } & \multirow{2}{*}{ 195} & 2.08 & 2.98 \\
\multirow{2}{*}{ Girls } & & .95 & 1.37 \\
& \multirow{2}{*}{215} & 2.43 & 2.31 \\
& & .92 & 1.13 \\
\hline
\end{tabular}

ANOVAs revealed statistically significant differences across gender for both mathematics curriculum $[\mathrm{F}(1,408)=14.46, \mathrm{p}<0.01]$ and mapping skill $[\mathrm{F}(1,408)=30.03$, $\mathrm{p}<0.01]$ variables. With respect to the mathematics curriculum variable, the girls were more likely to play with digital games that required problem solving, algorithmic computations or the interpretation of graphs than boys. By contrast, boys were more likely to play games that involved the interpretation of maps.

\section{$5 \quad$ Conclusion and Implications}

Buckingham (2007) acknowledged that students in today’s society are accessing technology in a variety of ways and with varying amounts on intensity, with access to technology increasingly disparate. Moreover, it is generally agreed that digital games are more likely to interest boys than girls_ or at least that boys and girls will have different levels of investment in different types of games (Gee, 2007; Unlusoy, de Haan, Leseman, \& van Kruistum, 2010). The present investigation highlighted distinct differences in the types of games boys and girls elect to play and begin to explain the influence game choice can have on students' mathematical engagement-particularly sense making in out-ofschool contexts.

Boys, for example, tend to choose games that require higher levels of spatial reasoning. These games are often adventure games which have a journey-based storyline and require a range of visual and spatial reasoning skills in order to make decisions about direction, locations and sequencing. By contrast, girls tend to prefer to play digital games that require computational accuracy and logic-based problem solving.

There is an extensive body of literature (e.g., Lowrie \& Diezmann, 2011; Lowrie \& Diezmann, 2007) that shows that boys outperform girls on mathematics items that require the interpretation of spatial information — and particularly tasks that required the interpretation of map-based graphics. It was noteworthy that these studies revealed gender 
differences across tasks that required the interpretation of location and positional information but not on other forms of graphics tasks (e.g., graphics tasks that displayed graphs, pie charts and flow charts). The present investigation highlighted the fact that boys not only prefer to play digital games that require the interpretation of map-based graphics but that these games provide a catalyst for other forms of mathematics engagement and sense making. Consequently, these games foster another rich context for students to think mathematically_-from both game playing and related-context perspectives.

There is a need, therefore, to develop spatially challenging games that have appeal for girls. The research literature suggests that girls enjoy in-depth stories and characters within game-playing contexts-particularly if there are opportunities for social interaction both on screen and with others (Inkpen et al., 1994; Murray and Kliman, 1999). Game playing story lines need accommodate these social interaction elements however they should also promote sense making that requires the encoding and decoding of graphics through visuospatial thinking. Visual and spatial thinking is becoming increasingly important and relevant to mathematics, particularly in concept development (Lowrie \& Diezmann, 2009), so increased exposure to such thinking should narrow the gap in terms of gender performance on mathematics tasks.

\section{Acknowledgments}

We would like to thank Tracy Logan for her insights, support and advice on the collaboration of data and dissemination of research for this article.

The work represented in this paper was supported by an Australian Research Council (ARC) Grant [DP0987253]. The views and ideas drawn from the research are that of the authors and not the ARC.

\section{References}

Bananno, P., \& Kommers, P. A. M. (2005). Gender differences and styles in the use of digital games. Educational Psychology, 25(1), 13-41.

Brain Training [Game]. (2006). Kyoto, Japan: Nintendo. 
British Educational Technologies and Communications Agency (BECTA) (2002). Young people's use of ICT questionnaire. Retrieved March 16, 2009 from http://www.becta.org.uk/youngpeopleict/

Buckingham, D. (2007). Beyond technology: Children's learning in the age of digital culture. Cambridge, UK: Polity Press.

Buzz! [Game]. (2005). London: Sony Computer Entertainment Europe.

Fennema, E. (1996). Scholarship, gender and mathematics. In P F Murphy, P F \& C V Gibbs (Eds.), Equity in the classroom: Towards effective pedagogy for girls and boys (pp 73-80). London: Falmer Press.

Forgasz, H. J., Leder, G. C., \& Kaur, B. (2001). Who can(t) do maths - boys/girls? Beliefs of Australian and Singaporean secondary school students. Asia Pacific Journal of Education, 21(2), 106-116.

Forgasz, H. J., Leder, G. C., \& Kloosterman, P. (2004). New perspectives on the gender stereotyping of mathematics. Mathematical Thinking and Learning, 6, 389-420.

Gee, J. P. (2007). What video games have to teach us about learning and literacy. Basingstoke: Palgrave Macmillan.

Guven, B., \& Kosa, T. (2008). The effect of dynamic geometry software on student mathematics teachers' spatial visualization skills. Turkish Online Journal of Educational Technology, 7(4), 100-107.

Hair, J. F., Jr., Anderson, R. E., Tatham, R. L., \& Black, W. C. (1998). Multivariate Data. Analysis ( $5^{\text {th }}$ ed.). Upper Saddle River: Prentice Hall.

Halpern, D. F., \& Tan, U. (2001). Stereotypes and steroids: Using a psychobiosocial model to understand cognitive sex differences. Brain and Cognition, 45, 392-414.

Hartmann, T. (2003, November 4-6). Gender differences in the use of computer-games as competitive leisure activities. Poster presented at the Digital Games Research Association (DIGRA) Conference, Utrecht, The Netherlands.

Inkpen, K., Upitis, R., Klawe, M., Lawry, J., Anderson, A., Ndunda, M., Sedighian, K., Leroux, S., Hsu, D. (1994). “We have never forgetful flowers in our garden”: Girls' responses to electronic games. Journal of Computers in Math and Science Teaching, 13(4), 383-403. 
Jarrell, R. H. (1998). Play and its influence on the development of young children's mathematical thinking. In D. Pronin Fromberg \& D Bergen (Eds.), Play from birth to twelve and beyond (pp. 56-67). New York: Garland Publishing Inc.

Levine, S. C., Huttenlocher, J., Taylor, A., \& Langrock, A. (1999). Early sex differences in spatial skill. Developmental Psychology, 35, 940-949.

Linn, M., \& Petersen, A. (1985). Emergence and characterization of sex differences in spatial ability: a meta-analysis. Child Development, 56, 1479-1498.

Lowrie, T. (2002). The influence of visual and spatial reasoning in interpreting simulated 3D worlds. International Journal of Computers for Mathematical Learning, 7, 301318.

Lowrie, T. (2003). Posing problems in ICT-based contexts. In L. Bragg, C. Campbell, G. Herbert, \& J. Mousley (Eds.), Mathematics education research: Innovation, networking, opportunity. Proceedings of the 26th Annual Conference of the Mathematics Education Group of Australasia, (pp. 499-506). Geelong, VIC: MERGA.

Lowrie, T., \& Diezmann, C. M. (2010). Solving graphics tasks: Gender differences in middle-school students. Learning and Instruction.

Lowrie, T., \& Diezmann, C. M. (2009). National numeracy tests: A graphic tells a thousand words. Australian Journal of Education. 53(2), 141-158.

Lowrie, T., \& Diezmann, C. M. (2007). Solving graphics problems: Student performance in the junior grades. The Journal of Educational Research, 100(6), 369-377.

Lowrie, T., \& Logan, T. (2007). Using spatial skills to interpret maps: Problem solving in realistic contexts. Australian Primary Mathematics Classroom, 12(4), 14-19.

Medal of honor [Game]. (1999). Redwood City, CA: Electronic Arts.

Murray, M., \& Kliman, M. (1999). Beyond point and click: The search for gender equity in computer games. ENC focus 6(3), 23-27.

National Council of Teachers of Mathematics. (2000). Principles and standards for school mathematics. Reston, VA: Author.

Quaiser-Pohl, C., Geiser, C., \& Lehmann, W. (2006). The relationship between computergame preference, gender, and mental-rotation ability. Personality and Individual Differences, 40(3), 609-619.

Spelke, E. S. (2005). Sex differences in intrinsic aptitude for mathematics and science? A critical review. American Psychologist, 60, 950-958 
Spyro [Game]. (2008). Santa Monica, CA: Activision Inc.

Tracey, D. A. (1990). Toys, spatial ability, and science and mathematics achievement: Are they related? Sex Roles, 17, 115-137.

Unlusoy, A., de Haan, M., Leseman, P.M., \& van Kruistum, C. (2010). Gender differences in adolescents’ out-of-school literacy practices: A multifaceted approach. Computers and Education, 55(2), 742-751.

van Oers, B. (2010). Emergent mathematical thinking in the context of play. Educational Studies in Mathematics, 74, 23-37.

Wiedenbauer, G., \& Jansen-Osmann, P. (2008). Manual training of mental rotation in children. Learning and Instruction, 18, 30-41.

Zevenbergen, R. \& Logan, H. (2008). Computer use by preschool children: Rethinking practice as digital natives come to preschool. Australian Journal of Early Childhood. 33(1), 37-44.

Zevenbergen, R. (2007). Digital Natives come to preschool: Implications for early childhood practice. Contemporary Issues in Early Childhood, 18(1). 19-29

Ziemek, T. R. (2006). Two-D or not Two-D: gender implications of visual cognition in electronic games. Proceedings of the 2006 symposium on Interactive 3D graphics and games. Redwood City, California: ACM. 